\title{
A High-Throughput Assay for Screening of Natural Products that Enhanced Tumoricidal Activity of NK Cells
}

\author{
Chenyuan Gong ${ }^{\dagger}$, Zhongya $\mathrm{Ni}^{\dagger}$, Chao Yao, Xiaowen Zhu, Lulu Ni, Lixin Wang and Shiguo Zhu*
}

\begin{abstract}
Background: Recently, immunotherapy has shown a lot of promise in cancer treatment and different immune cell types are involved in this endeavor. Among different immune cell populations, NK cells are also an important component in unleashing the therapeutic activity of immune cells. Therefore, in order to enhance the tumoricidal activity of NK cells, identification of new small-molecule natural products is important. Despite the availability of different screening methods for identification of natural products, a simple, economic and high-throughput method is lacking. Hence, in this study, we have developed a high-throughput assay for screening and indentifying natural products that can enhance NK cell-mediated killing of cancer cells.
\end{abstract}

Results: We expanded human NK cell population from human peripheral blood mononuclear cells (PBMCs) by culturing these PBMCs with membrane-bound IL-21 and CD137L engineered K562 cells. Next, expanded NK cells were co-cultured with non-small cell lung cancer (NSCLC) cells with or without natural products and after $24 \mathrm{~h}$ of co-culturing, harvested supernatants were analyzed for IFN- $\gamma$ secretions by ELISA method. We screened 502 natural products and identified that 28 candidates has the potential to induce IFN- $\gamma$ secretion by NK cells to varying degrees. Among the 28 natural product candidates, we further confirmed and analyzed the potential of one molecule, andrographolide. It actually increased IFN- $\gamma$ secretion by NK cells and enhanced NK cell-mediated killing of NSCLC cells.

Conclusions: Our results demonstrated that this IFN- $\gamma$ based high-throughput assay for screening of natural products for NK cell tumoricidal activity is a simple, economic and reliable method.

Keywords: Natural products, NK cells, High-throughput screening, IFN- , Andrographolide

\section{Background}

Natural killer (NK) cells are derived from hematopoietic progenitor cells and are abundantly present in bone marrow, various organs and even in secondary lymphoid tissues [1]. They constitute nearly 10-15\% of PBMCs and are usually defined by expression of CD56 and CD16 proteins, but lacks CD3 [2, 3]. NK cells are a critical component of the innate immune response against tumor cells and infections [4-6]. The tumoricidal activity of NK cells is mediated by release of, a) various cytokines such as IFN- $\gamma$ and TNF- $\alpha, b)$ exocytosis of

\footnotetext{
*Correspondence: jusco105@163.com

†Equal contributors

Laboratory of Integrative Medicine, School of Basic Medical Sciences,

Shanghai University of Traditional Chinese Medicine, 1200 Cai Lun Road,

Shanghai 201203, P.R. China
}

granzymes (Perforin) containing lytic granules [7], and c) expression of some death receptor ligands [8]. NK cells recognition and destruction of tumor cells does not involve prior sensitization in an MHC-I-unrestricted manner [9]. Thus, NK cells immunotherapy have shown a great potential in most of the hematopoietic malignancies [10].

There have been innumerable attempts over years to use NK cell immunotherapy for the treatment of solid cancers without much success. NK cells-mediated targeting of solid tumor is usually not efficient despite of the tumor cells expressing high amounts of activating and low levels of inhibitory ligands [11]. This is attributed to the creation of an immunosuppressive environment by cancer cells to evade NK cell immune surveillance, through secretion of factors like TGF- $\beta[12,13]$. Thus, it leads to poor prognosis [14]. The escape of tumor cells

\section{Biomed Central}

(c) 2015 Gong et al. Open Access This article is distributed under the terms of the Creative Commons Attribution 4.0 International License (http://creativecommons.org/licenses/by/4.0/), which permits unrestricted use, distribution, and reproduction in any medium, provided you give appropriate credit to the original author(s) and the source, provide a link to the Creative Commons license, and indicate if changes were made. The Creative Commons Public Domain Dedication waiver (http://creativecommons.org/publicdomain/zero/1.0/) applies to the data made available in this article, unless otherwise stated. 
from immunosuppressive cells like NK cells, leads to the failure of the immunotherapy especially for solid tumors in the clinical settings. Hence, the development of new drugs with ability to block the immunosuppressive environment is required to efficiently block the escaping of tumor cells from immunosuppressive cell and will help in restoring NK cell-mediated anti-tumor response [15].

Small-molecules isolated from natural products are a major source for the development of new drugs. So far, almost $50 \%$ of all the new drugs were either natural products or their analogs, including those that modulate immune cell functions [16]. Natural products that enhance NK cell antitumor activity can block the escaping of tumor cells from immune response and restore NK cell mediated antitumor activity. However, lack of simple and economic approach for large scale screening of the natural products has been a big impediment and thus warrants a development of a novel high-throughput assay for screening of novel and efficient small molecules from a pool of thousands of natural products.

IFN- $\gamma$ is a major cytokine secreted by activated NK cells and exerts immune response against cancer and virus-infected cells by inducing tumor apoptosis $[17,18]$. IFN- $\gamma$ has is a potent indicator of NK cell activity. Bellucci R. et al. showed that silencing of 83 genes in tumor cells resulted in enhanced IFN- $\gamma$ release from NKL cells and thus promoted apoptosis [19]. Similarly, Lee SB. et al. also assessed NK cell activity as a function of IFN- $\gamma$ secretion in whole blood samples [20]. Therefore, in this study, we also developed an IFN- $\gamma$ based high-throughput assay screen for assessing the effect of small-molecule natural products on the tumoricidal activity of NK cells. After screening 502 natural products, we identified 28 candidates with a potential to enhance NK cell activity and further confirmed that andrographolide, one among the 28 natural products, actually induced IFN- $\gamma$ secretion by NK cells, and enhanced NK cell mediated killing of cancer cells.

\section{Results}

\section{Human NK Cell Expansion}

In clinical application, there is always a requirement of high number of NK cells and therefore, we first expanded the NK cell population by an efficient system developed by us previously for NK cell expansion [21]. The CD137L and membrane-bound IL-21 engineered K562 were irradiated and then co-incubated with PBMCs for 2 weeks. Results showed that about $99 \%$ of $\mathrm{CD}^{-}{ }^{-} \mathrm{CD} 56^{+}$cells were NK cells after 2-week of expansion. Among these NK cells, majority of them were $\mathrm{CD}^{2} 6^{+} \mathrm{CD} 16^{+}$cells (>95\%) (Fig. 1). These results were consistent with our previous result, and indicated that these expanded NK cells were of high purity, and were subsequently used for screening of natural products (Fig. 2).

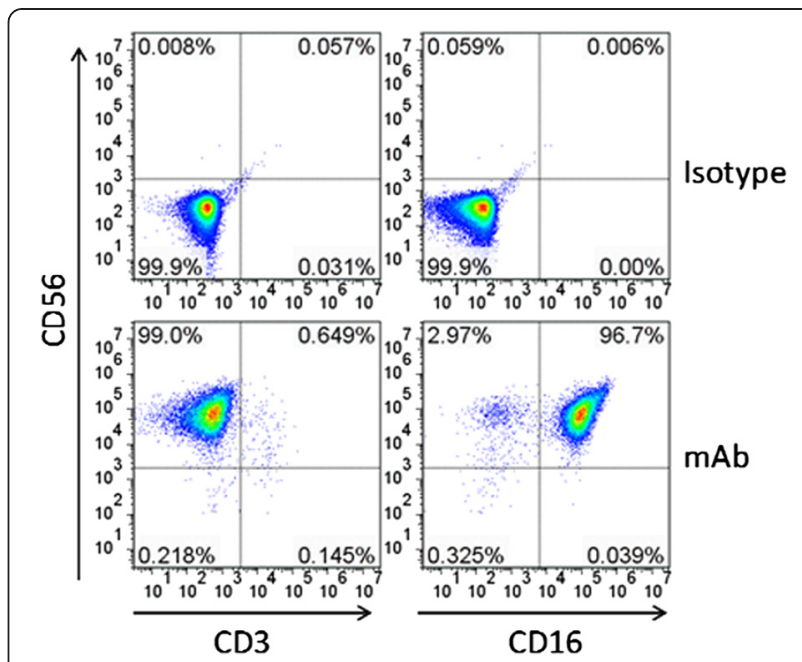

Fig. 1 Expansion of human NK cells. NK cells were expanded as described in Methods section, and were stained with CD56, CD16 and CD3 antibodies for flow cytometry analysis. The data set presented here is a representative of three independent experiments

Optimization of Co-culturing Conditions for Maximum NK Cell Tumoricidal Response

NK cells release IFN- $\gamma$ after recognizing and binding to the target cells. The level of IFN- $\gamma$ production is directly proportional with NK cell tumoricidal activity. Therefore, we first optimized the E:T ratio of NK cells (effector) and A549 tumor cells (target) for inducing efficient tumoricidal activity. Herein, we used IL-2 as a positive activator/stimulator to induce NK cells cytotoxic activity by co-culturing them with target cells. We mixed lung adenocarcinoma, A549 cells $\left(5 \times 10^{3}\right)$ per well together with different ratios of NK cells (NK cells: A549 cells $=0.5: 1,1: 1,2: 1,4: 1$ ) in 96-well plate either in the presence or absence of $100 \mathrm{U} / \mathrm{mL}$ of IL-2 for $24 \mathrm{~h}$. Subsequently, IFN- $\gamma$ secretion was measured in the supernatants. Results showed that secreted IFN- $\gamma$ was enhanced with the increasing ratio of NK cells to target cells after IL-2 stimulation and peaked at 2:1 ratio (Fig. 3). These results demonstrated that $0.5 \times 10^{4}$ of A549 cells mixed with $1 \times 10^{4}$ of NK cells could elicit maximal IFN- $\gamma$ secretion after IL-2 stimulation, thus, indicating that this E:T ratio is optimum for screening of natural products.

\section{Screening of Natural Products for Induction of NK Cell Tumoricidal Activity}

To determine the efficiency of 502 natural products to induce NK cell tumoricidal activity, we plated $1 \times 10^{4}$ of expanded NK cells from 3 donors and $5 \times 10^{3}$ of A549 cells per well in 96-well plates. Thereafter, these co-cultured cells were treated with each of the natural products at a final concentration of $10 \mu \mathrm{M}$. At parallel, the cells were also treated with equal volume of DMSO as negative 


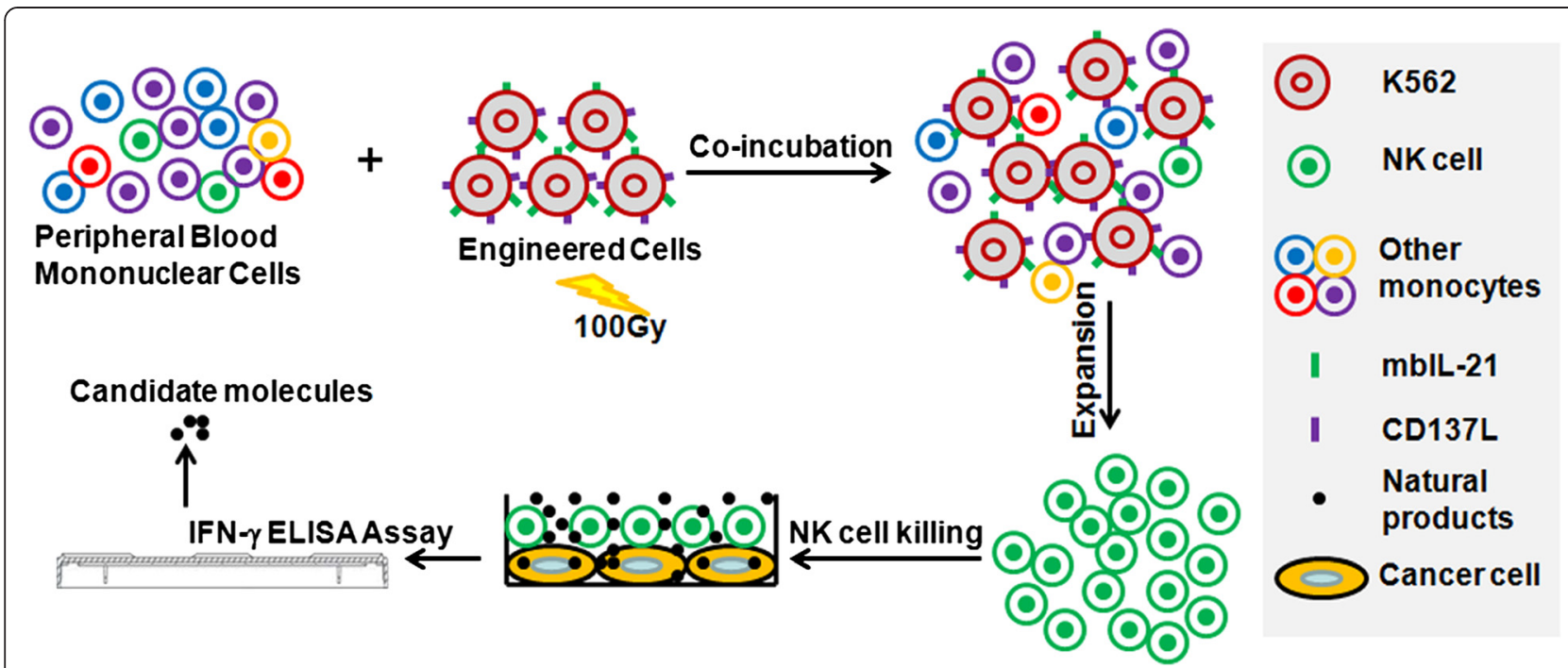

Fig. 2 The schematic presentation of IFN- $\gamma$ based high-throughput assay for screening of natural products. To identify potent natural products, human NK cells were first expanded, and then co-incubated with A549 cells in 96-well plates with or without natural products. After $24 \mathrm{~h}$ of co-culturing, supernatants were harvested and IFN- $\gamma$ levels were measured by ELISA assay

control and $100 \mathrm{U} / \mathrm{mL}$ of IL-2 as a positive control. We arbitrarily used $\geq 40 \%$ increase in IFN- $\gamma$ secretion, in comparison to the negative control, as efficient criteria. Based on this criterion, we identified that 28 natural products induced an efficient increase in IFN- $\gamma$ secretion (Fig. 4a). Comparison of IFN- $\gamma$ secretion induced by 28 natural products and corresponding IL-2 stimulations, we found that IFN- $\gamma$ secretion by 5 natural products were $<20 \%$ of the levels induced by IL-2, whereas 14 natural products showed $20 \%-50 \%$ of the IFN- $\gamma$ secretion in comparison to IL-2 induction (Fig. 4b). Interestingly, 2 natural products displayed $50 \%-100 \%$ of IFN- $\gamma$ secretion and 7 natural products had $>100 \%$ secretion in comparison to IL-2 induced IFN- $\gamma$ secretion. Among

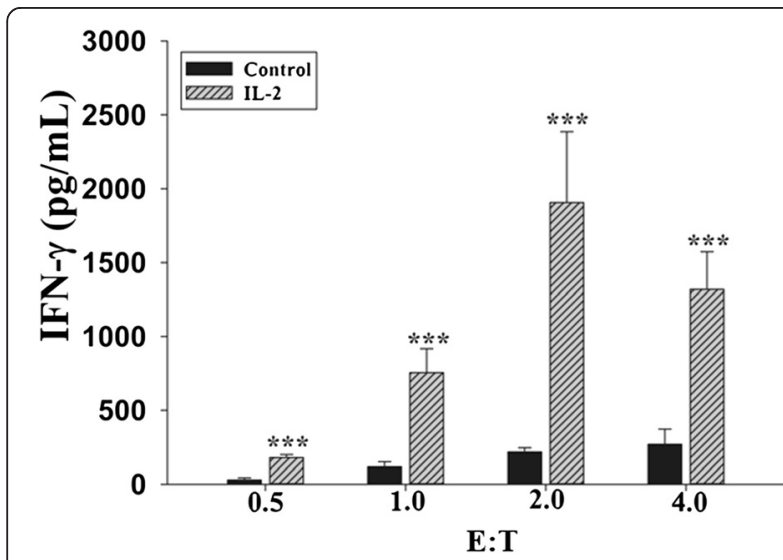

Fig. 3 Optimization of NK and target (A549) cells culturing conditions. NK cells were co-cultured with A549 cells at different E:T ratios in 96-well plates for $24 \mathrm{~h}$, and then IFN- $\gamma$ secretion in supernatant was detected by ELISA assay. The data shown here is a representative of three independent experiments. ${ }^{* *}, P<0.001$ these 7 natural products, 6 of them were protein kinase $C$ activators and another natural product was unknown.

\section{Effect of Andrographolide on Viability of NK and NSCLC Cells}

Andrographolide, one among the 28 natural products, has been found to suppress vascular angiogenesis and tumor growth in our previous studies [22]. This led us to further analyze this natural product and we investigated its effects on NK cells and NSCLC cells viability. Expanded NK cells and different NSCLC cell lines (A549, H1299 and H1975) were treated with different concentrations of andrographolide $(0,1,5,10,25$ and 50 $\mu \mathrm{M})$. Results showed that all selected doses of andrographolide did not impair NK cells viability at $24 \mathrm{~h}$ time point. But $50 \mu \mathrm{M}$ concentration of andrographolide had $20 \%$ inhibition $(p<0.05)$ at $48 \mathrm{~h}$; and 10,25 and $50 \mu \mathrm{M}$ of andrographolide had $15 \%, 20 \%$ and $30 \%$ inhibition $(p<0.05)$ at $72 \mathrm{~h}$ (Fig. 5a). On the other hand, andrographolide above $2.5 \mu \mathrm{M}$ significantly $(p<0.001)$ suppressed the cell viability of all NSCLC cell lines at all time points (Fig. 5b). These results thus indicate that andrographolide has low toxicity towards expanded NK cells, but has higher toxicity against NSCLC cells.

\section{Role of Andrographolide in Inducing NK Cell Mediated IFN- $\gamma$ Secretion and Killing}

Since low doses of andrographolide did not inhibit the cells viability of expanded NK cells but had significant suppression in NSCLC cells, we next focused on determining its effect on NK cell tumoricidal activity. We first incubated NK cells and A549 cells together with different concentrations of andrographolide for $24 \mathrm{~h}$, and then 


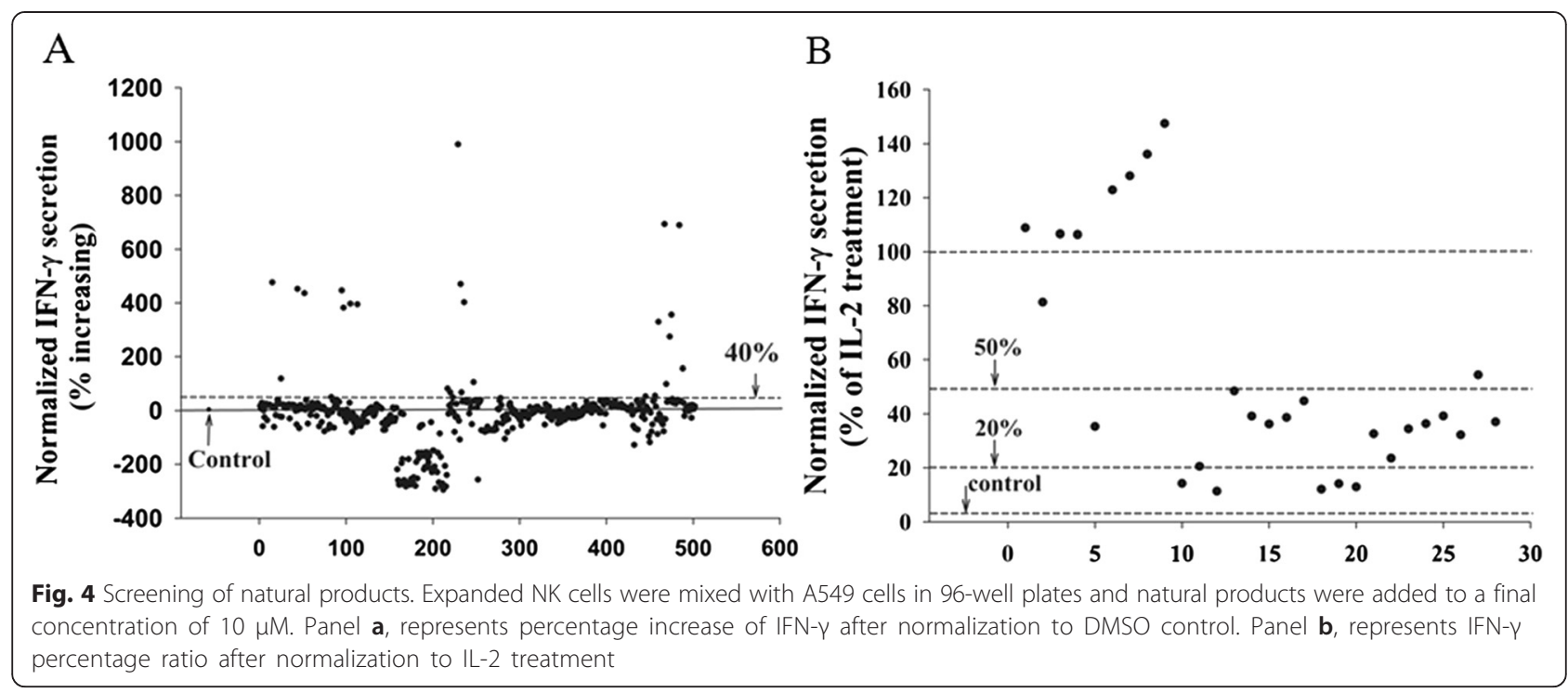

detected IFN- $\gamma$ release by NK cells. The results showed that andrographolide increased IFN- $\gamma$ release, which was not clearly dose-dependent (Fig. 6). Next, we determined if andrographolide enhanced the NK cell-mediated lysis of NSCLC cells by calcein release assay. Here we pretreated the A549 and H1299 NSCLC cells with 5 and $10 \mu \mathrm{M}$ of andrographolide for $24 \mathrm{~h}$, respectively. Later these andrographolide pretreated NSCLC cells were incubated with untreated NK cells and we observed that NK cells significantly enhanced the lysis of andrographolide treated A549 and H1299 cells. Further, we pretreated the NK cells with andrographolide and then incubated them with untreated NSCLC cells, and again observed a significant enhancement of NK cell mediated lysis of A549 cells and H1299 cells. Finally, we pretreated both NSCLC cells and NK cells, respectively; and then incubated them together, and observed this time also a significant enhancement of NK cell killing (Fig. 7a, b). Taken together, these results indicated that andrographolide treatment has the potential to enhance NK cell tumoricidal activity.

\section{Discussion}

In this study, we developed an IFN- $\gamma$-based highthroughput screening assay to screen natural products which might enhance NK cell mediated lysis of cancer cells. By measuring the IFN- $\gamma$ release by NK cells, we totally screened 502 natural products and identified that 28 natural products could increase IFN- $\gamma$ release.

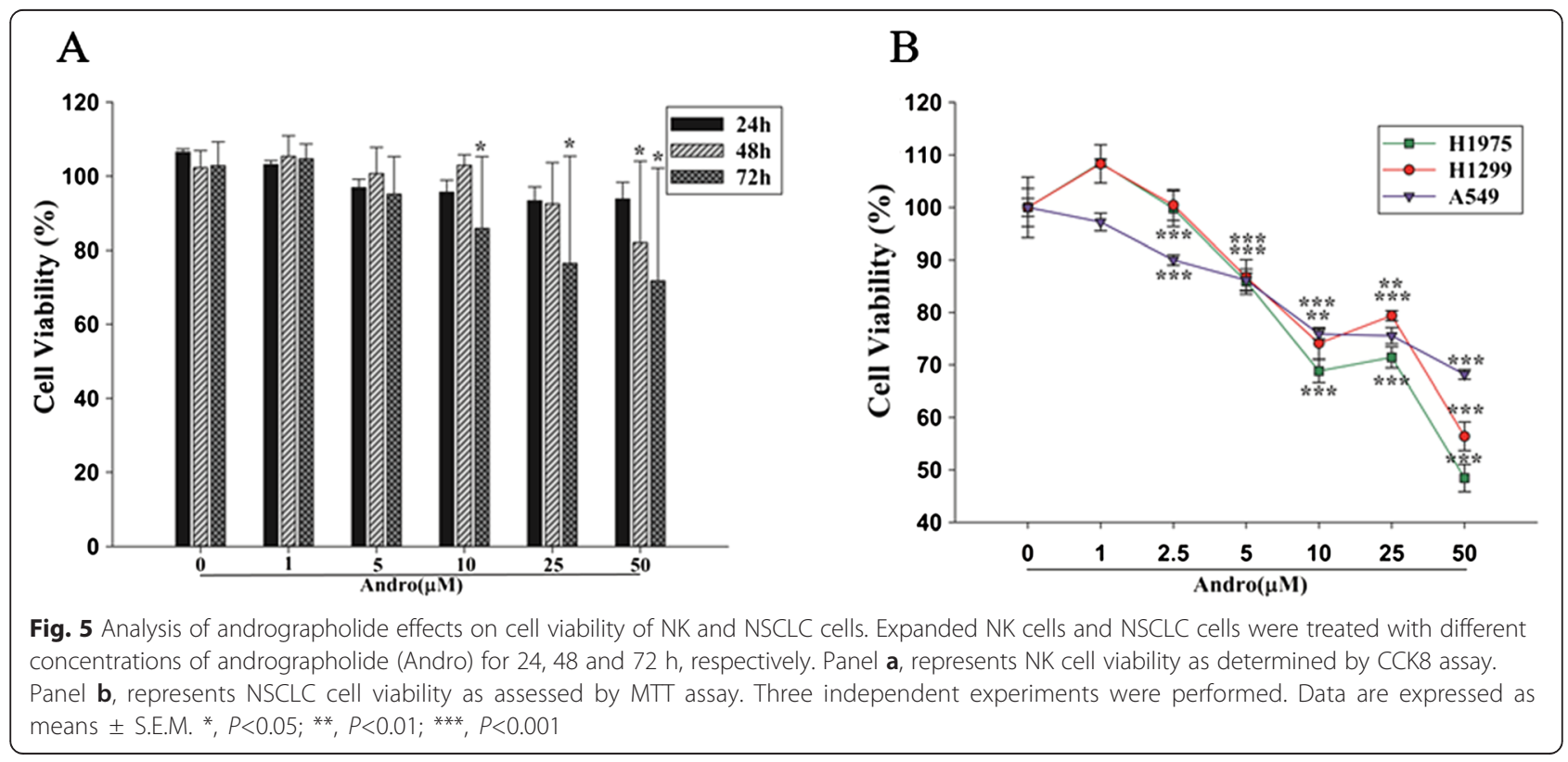




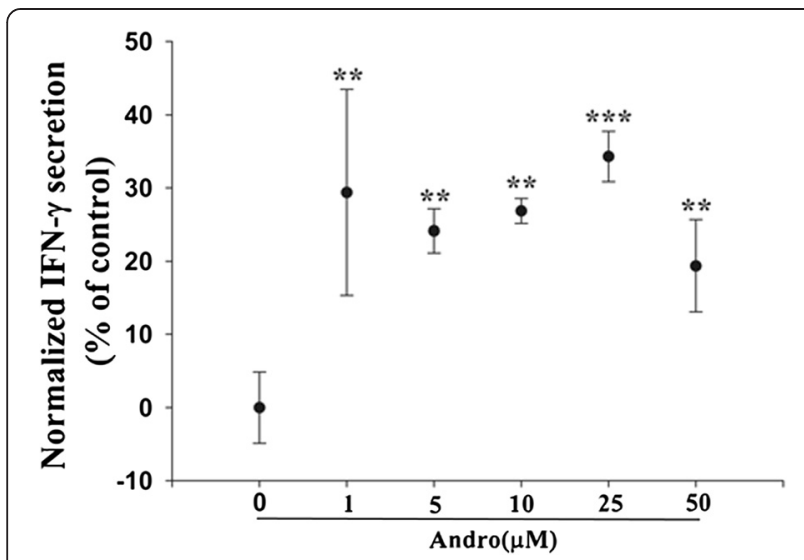

Fig. 6 Andrographolide increased IFN- $\gamma$ secretion by NK cells. Expanded NK cells and A549 cells were co-cultured with various concentrations (1 $\mu \mathrm{M}$ to $50 \mu \mathrm{M})$ of andrographolide. After $24 \mathrm{~h}$, IFN- $\gamma$ release in supernatant was measured by ELISA method

Andrographolide, one among 28 natural products, displayed low toxicity in expanded NK cells but had higher toxicity against different NSCLC cells. But, andrographolide not only induced IFN- $\gamma$ release but also enhanced NK cell mediated killing of tumor cells. These results thus established that the IFN- $\gamma$-based screening assay is a viable option for screening and identifying natural products that has the potential to enhance NK cell mediated killing of cancer cells.

Previously published studies have shown that natural products are a good source of compounds that can improve NK cell anti-tumor response by enhancing NK cell mediated recognition and killing of cancer cells [23-27]. However, it was hard to find efficient candidates from millions of natural products [28]. Numbers of different methods have been developed so far to detect NK cell cytotoxicity. For example, Chromium 51 release assay is the standard method to determine NK cells cytolytic activity. In addition, CD107 $\alpha$ degranulation assay and several flow cytometric methods were also alternatively used to determine NK cell cytotoxicity [29]. However each of these assays had certain limitations, for example, chromium 51 release assay were high-cost, involved hazardous radioactivity and generated radioactive waste [30], whereas CD107 $\alpha$ degranulation assay and other flow cytometric methods were time consuming and involved high cost, and more importantly, all these methods were not suitable for high-throughput analysis [31]. Furthermore, these methods only focused on the final NK cell killing activity on cancer cells, and totally ignored, the inhibitory influence of cancer microenvironment, such as IDO (Indoleamine-2,3-dioxygenase), PGE2 (Prostaglandin E2), and other factors secreted by cancer cells against NK cells [32]. Therefore, the development of a high-throughput screening assay that could mimic the cancer microenvironment was necessary for identification of natural products that has the potential to modulate NK cell activity.

IFN- $\gamma$ is a good indicator of NK cell cytotoxicity and has been used to determine the NK cells anti-tumor activity in whole blood [20]. In this study, we had developed an IFN- $\gamma$-based assay to determine NK cell killing activity in an in vitro NK cell-cancer cell interacting microenvironment. To get an optimal IFN- $\gamma$ response, we optimized $\mathrm{E} / \mathrm{T}$ ratio and found the best $\mathrm{E} / \mathrm{T}$ ratio was 2. This $E / T$ ratio may change in different cancer model and was not equal to the best killing effect. In

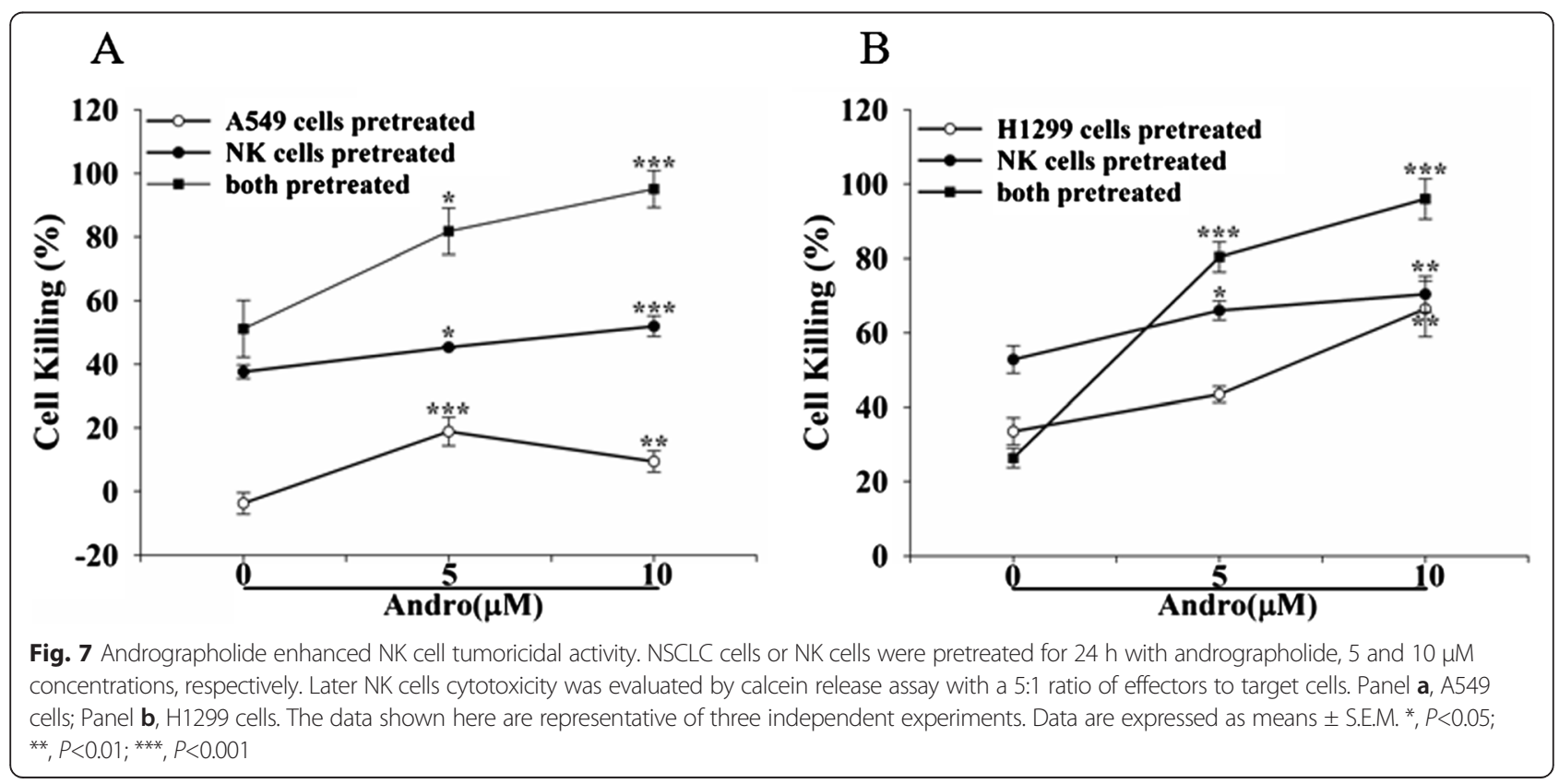


fact, more NK cells may exert much higher killing efficacy, but the IFN- $\gamma$ response may be not optimal. As shown in Fig. 3, INF- $\gamma$ product become lower at E/T ratio 4 compared to $\mathrm{E} / \mathrm{T}$ ratio 2 . We analyzed 502 natural products for induction of IFN- $\gamma$ release by NK cells and identified that 28 natural products induced $40 \%$ increase compared to no treatment. Among these natural products, 7 induced higher IFN- $\gamma$ secretions than IL-2 stimulation and out of these 7 natural products, 6 were protein kinase $\mathrm{C}$ activators. This result was consistent with previous published reports that protein kinase $\mathrm{C}$ activation could increase IFN- $\gamma$ secretion [33], and suggested that protein kinase $\mathrm{C}$ may be a good target for natural products-induced NK cell activation $[34,35]$.

Andrographolide, one among the 28 natural products had been demonstrated to have anti-inflammatory, anticancer and angiogenesis activities both in vitro and in vivo $[22,36]$. In this study, andrographolide was shown to have a low toxicity towards expanded NK cells, but displayed higher toxicity against NSCLC cells, which was consistent with its anti-tumor effects. In addition, andrographolide really enhanced IFN- $\gamma$ release by NK cells and also NK cell-mediated killing of NSCLC cells, and this enhancement was dose-independent. Doseindependent effect is a common phenomenon. Fox example, small-molecule antagonist BIO-1211 (Very Late Antigen-4 (VLA4) blocker) results in reduced cytokines expression, leukocyte trafficking, and inhibition of inflammatory responses in EAE in a dose-independent manner [37]. Of course, the mechanism is complicated and additional experiments are needed to further define. Taken together, our results suggested that andrographolide might have a potent application in NK cell immunotherapy, and that the IFN- $\gamma$ based high-throughput screening assay can be a reliable method.

\section{Conclusions}

In this study, we developed a simple and economic, IFN- $\gamma$ based high-throughput screening assay to identify natural products that could enhance the NK cells tumoricidal activity. Furthermore, with the application of this assay, we identified 28 natural product candidates. This highthroughput screening assay might have valuable application in NK cell-based drug discovery, and the 28 natural product candidates can have potent application in modulation of NK cell function and immunotherapy.

\section{Methods}

\section{Reagents}

APC anti-human CD56, FITC anti-human CD3, PE antihuman CD16, murine isotype controls (IgG1k-PE, IgG1אFITC, IgG2a -APC) and human IFN- $\gamma$ ELISA MAX ${ }^{\mathrm{m}}$ Deluxe kit were purchased from BioLegend Inc. (San Diego, CA). The recombinant human IL-2 protein was obtained from PeproTech (Rehovot, Israel). Calcein-AM was purchased from Sigma-Aldrich (St, Louis, MO). CCK8 kit was purchased from YESAN (Shanghai, China).

\section{NK Cell Expansion}

Human peripheral blood mononuclear cells (PBMC) were obtained from the Shanghai Blood Center under a research protocol approved by the Department of Shanghai Blood Administration. PBMCs were either freshly used or frozen in $10 \%$ DMSO containing fetal bovine serum (FBS, Gibco). Frozen PBMCs were thawed, one day prior to their cultivation in RPMI1640 medium supplemented with $10 \%$ of fetal calf serum, $1 \%$ of penicillin-streptomycin, 2 $\mathrm{mM}$ of L-Glutamine and $200 \mathrm{U} / \mathrm{ml}$ of IL-2 in $5 \% \mathrm{CO} 2$ at $37{ }^{\circ} \mathrm{C}$. NK cells were expanded as described previously [21]. Briefly, fresh or frozen PBMCs were co-incubated with mbIL-21-CD137L-K562 cells which were pretreated by 100 Gy irradiation for 2 weeks in RPMI1640 complete medium in $5 \% \mathrm{CO} 2$ at $37{ }^{\circ} \mathrm{C}$.

\section{Flow Cytometry Analysis}

Cells were incubated with CD56, CD16 and CD3 antibodies conjugated with different fluorophores for $30 \mathrm{~min}$ at $4{ }^{\circ} \mathrm{C}$ in dark, followed by washing, and resuspension in PBS containing $1 \%$ FBS. Data were acquired using a BD Accuri C6 (BD Biosciences) and analyzed using the FlowJo software (Ashland, OR).

\section{Screening Assay}

Total of 502 natural products were obtained from China National Compound Resource Center (NCRC). The NK cells $\left(1 \times 10^{4}\right)$ from 3 donors were mixed with A549 lung adenocarcinoma cells $\left(5 \times 10^{3}\right)$ per well in 96-well plates. These co-cultured cells were treated with natural products to a final concentration of $10 \mu \mathrm{M}$. Equal volume of DMSO was added as negative control and $100 \mathrm{U} / \mathrm{mL}$ of IL-2 was added as positive stimulator. After $24 \mathrm{~h}$ of incubation, supernatants were harvested and IFN- $\gamma$ was measured by Human IFN- $\gamma$ ELISA Kit following the manufacturer's instructions. Briefly, IFN- $\gamma$ (capture) antibody was incubated in 96 -well plates at $4{ }^{\circ} \mathrm{C}$ overnight. The plates were then washed 3 times with PBS containing $0.1 \%$ Tween-20, incubated with blocking buffer for $1 \mathrm{~h}$, and then washed 3 times again with PBS containing $0.1 \%$ Tween-20. Supernatant were added to each well and incubated for $2 \mathrm{~h}$, followed by washing of plates again 3 times with PBS containing $0.1 \%$ Tween20. Next, detection antibody was added and plates were incubated for $1 \mathrm{~h}$. At last, HRP reagent was added for colorimetric detection of the signal and plates were read at $450 \mathrm{~nm}$ using Synergy 2 Multi-Mode Microplate Reader (BioTek Instruments, Inc., Winooski, VT). 


\section{Cell Viability Assay}

NK cells were seeded into 96-well plates at a density of $1 \times 10^{4}$ cells per well, and treated with different concentrations of andrographolide for 24, 48 and $72 \mathrm{~h}$. The cell viability was measured by CCK8 kit following manufacturer's instructions. Similarly, non-small cell lung cancer (NSCLC) cells $\left(5 \times 10^{3}\right.$ per well) were seeded into 96-well plates and treated with different concentrations of andrographolide for 24, 48 and $72 \mathrm{~h}$. After treatment, cells were incubated with $500 \mu \mathrm{g} / \mathrm{mL}$ of MTT [3-(4,5-dimethyl-2thiazolyl)-2,5-diphenyl-2-H-tetrazolium bromide] for $4 \mathrm{~h}$, and the supernatants were removed. The plates were read at $490 \mathrm{~nm}$ using Synergy 2 Multi-Mode Microplate Reader (BioTek Instruments, Inc., Winooski, VT).

\section{Calcein Release Assay}

NK cells cytotoxicity were determined by using the calcein release fluorometric assay [38, 39]. A549 cells were incubated with $2 \mu \mathrm{g} / \mathrm{mL}$ of calcein-AM at $37^{\circ} \mathrm{C}$ for $1 \mathrm{~h}$ with occasional shaking. NK cells and A549 cells were mixed at effector-to-target (E:T) ratio of $5: 1\left(5 \times 10^{4}: 1 \times 10^{4}\right)$ and co-cultured for $4 \mathrm{~h}$. After incubation, $100 \mu \mathrm{L}$ of supernatant was transferred to a new plate. The fluorescence of samples was measured with a Synergy 2 Multi-Mode Microplate Reader (BioTek Instruments, Inc., Winooski, VT) (excitation filter $485 \mathrm{~nm}$, emission filter $538 \mathrm{~nm}$ ). The percentage lysis was calculated according to the formula [(experimental release - spontaneous release)/ (maximum release - spontaneous release) $] \times 100$.

\section{Statistical Analysis}

High-throughput screening assay was evaluated by Z'factor as described previously [29, 30]. Results with Z'-factor below zero were discarded.

$$
\mathrm{Z}^{\prime}=1-(3 * \mathrm{SDc}++3 * \mathrm{SDc}-) /(\mu \mathrm{c}+-\mu \mathrm{c}-)
$$

SDc+ standard deviation of IL-2 stimulated NK cell activity

SDc- standard deviation based on level of NK cell activity

$\mu \mathrm{c}+$ mean of IL-2 stimulated NK cell activity

$\mu \mathrm{c}-$ mean based on level of NK cell activity

Results are expressed as the mean \pm SEM. Statistical comparison in two groups was performed by Student's $t$ test. $P<0.05$ represented statistical significant differences.

\section{Competing interest}

The authors declare no competing interest.

\section{Authors' contributions}

CG and ZN carried out the screening and drafted the manuscript. $C Y$ participated in the experiments of andrographolide. XZ carried out the NK cell expansion. LN and LW performed the statistical analysis. SZ conceived of the study, and participated in its design and coordination and helped to draft the manuscript. All authors read and approved the final manuscript.

\section{Acknowledgments}

This study was supported by National Natural Science Foundation of China (81473237), the Shanghai Foundation for Development of Science and Technology (14431902600), the budget project of Shanghai Municipal Education Commission (2013JW01) and the pre-project of basic research and development programs of Shanghai University of Traditional Chinese Medicine (2013YY02)

Received: 25 September 2015 Accepted: 21 October 2015

Published online: 28 October 2015

\section{References}

1. Freud AG, Caligiuri MA. Human natural killer cell development. Immunol Rev. 2006;21:56-72. doi:10.1111/j.1600-065X.2006.00451.

2. Farag SS, Fehniger TA, Ruggeri L, Velardi A, Caligiuri MA. Natural killer cell receptors: new biology and insights into the graft-versus-leukemia effect. Blood. 2002;100(6):1935-47. doi:10.1182/blood-2002-02-0350.

3. Biassoni R. Natural killer cell receptors. Adv Exp Med Biol. 2008;640:35-52. doi:10.1007/978-0-387-09789-3_4.

4. Caligiuri MA. Human natural killer cells. Blood. 2008;112(3):461-9. doi:10.1182/blood-2007-09-077438.

5. Vivier E, Raulet $D H$, Moretta A, Caligiuri MA, Zitvogel L, Lanier LL, et al. Innate or adaptive immunity? The example of natural killer cells. Science. 2011;331(6013):44-9. doi:10.1126/science.1198687.

6. Ljunggren HG, Malmberg KJ. Prospects for the use of NK cells in immunotherapy of human cancer. Nat Rev Immunol. 2007;7(5):329-39. doi:10.1038/nri2073.

7. Trapani JA, Smyth MJ. Functional significance of the perforin/granzyme cell death pathway. Nat Rev Immunol. 2002;2(10):735-47. doi:10.1038/nri911 nri911.

8. Zamai L, Ahmad M, Bennett IM, Azzoni L, Alnemri ES, Perussia B. Natural killer (NK) cell-mediated cytotoxicity: differential use of TRAIL and Fas ligand by immature and mature primary human NK cells. J Exp Med. 1998;188(12):2375-80.

9. Guerra N, Tan YX, Joncker NT, Choy A, Gallardo F, Xiong N, et al. NKG2D-deficient mice are defective in tumor surveillance in models of spontaneous malignancy. Immunity. 2008;28(4):571-80. doi:10.1016/ j.immuni.2008.02.016.

10. Ames E, Murphy WJ. Advantages and clinical applications of natural killer cells in cancer immunotherapy. Cancer Immunol Immunother. 2013;63(1):21-8. doi:10.1007/s00262-013-1469-8.

11. Stojanovic A, Cerwenka A. Natural killer cells and solid tumors. J Innate Immun. 2011;3(4):355-64. doi:10.1159/000325465.

12. Hanahan D, Weinberg RA. Hallmarks of cancer: the next generation. Cell. 2011;144(5):646-74. doi:10.1016/j.cell.2011.02.013.

13. Flavell RA, Sanjabi S, Wrzesinski SH, Licona-Limon P. The polarization of immune cells in the tumour environment by TGFbeta. Nat Rev Immunol. 2010;10(8):554-67. doi:10.1038/nri2808.

14. Ikushima H, Miyazono K. TGFbeta signalling: a complex web in cancer progression. Nat Rev Cancer. 2010;10(6):415-24. doi:10.1038/nrc2853.

15. Friese MA, Wischhusen J, Wick W, Weiler M, Eisele G, Steinle A, et al. RNA interference targeting transforming growth factor-beta enhances NKG2D-mediated antiglioma immune response, inhibits glioma cell migration and invasiveness, and abrogates tumorigenicity in vivo. Cancer Res. 2004;64(20):7596-603. doi:10.1158/0008-5472.CAN-04-1627.

16. Martin-Fontecha A, Thomsen LL, Brett S, Gerard C, Lipp M, Lanzavecchia A, et al. Induced recruitment of NK cells to lymph nodes provides IFN-gamma for $T(H) 1$ priming. Nat Immunol. 2004;5(12):1260-5. doi:10.1038/ni1138.

17. Ikeda $\mathrm{H}$, Old $L$, Schreiber RD. The roles of IFN gamma in protection against tumor development and cancer immunoediting. Cytokine Growth Factor Rev. 2002;13(2):95-109.

18. Tu SP, Quante M, Bhagat G, Takaishi S, Cui G, Yang XD, et al. IFN-gamma inhibits gastric carcinogenesis by inducing epithelial cell autophagy and T-cell apoptosis. Cancer Res. 2011;71(12):4247-59. doi:10.1158/0008-5472.CAN-10-4009.

19. Bellucci R, Nguyen HN, Martin A, Heinrichs S, Schinzel AC, Hahn WC, et al. Tyrosine kinase pathways modulate tumor susceptibility to natural killer cells. J Clin Invest. 2012;122(7):2369-83. doi:10.1172/JCl58457.

20. Lee SB, Cha J, Kim IK, Yoon JC, Lee HJ, Park SW, et al. A high-throughput assay of NK cell activity in whole blood and its clinical application. Biochem Biophys Res Commun. 2014;445(3):584-90. doi:10.1016/j.bbrc.2014.02.040.

21. Wang $X$, Lee DA, Wang $Y$, Wang L, Yao $Y$, Lin $Z$, et al. Membrane-bound interleukin-21 and CD137 ligand induce functional human natural killer cells 
from peripheral blood mononuclear cells through STAT-3 activation. Clin Exp Immunol. 2013;172(1):104-12. doi:10.1111/cei.12034.

22. Gong C, Xu C, Ji L, Wang Z. A novel semi-synthetic andrographolide analogue A5 inhibits tumor angiogenesis via blocking the VEGFR2-p38/ ERK1/2 signal pathway. Biosci Trends. 2013;7(5):230-6.

23. Armeanu S, Bitzer M, Lauer UM, Venturelli S, Pathil A, Krusch M, et al. Natura killer cell-mediated lysis of hepatoma cells via specific induction of NKG2D ligands by the histone deacetylase inhibitor sodium valproate. Cancer Res. 2005;65(14):6321-9.

24. Kim HR, Kim K, Lee KH, Kim SJ, Kim J. Inhibition of casein kinase 2 enhances the death ligand- and natural kiler cell-induced hepatocellular carcinoma cell death. Clin Exp Immunol. 2008;152(2):336-44. doi:10.1111/j.1365-2249.2008.03622.x.

25. Bae JH, Kim JY, Kim MJ, Chang SH, Park YS, Son CH, et al. Quercetin enhances susceptibility to NK cell-mediated lysis of tumor cells through induction of NKG2D ligands and suppression of HSP70. J Immunother. 2010:33(4):391-401. doi:10.1097/CJl.0b013e3181d32f22.

26. Quoc Trung L, Espinoza JL, Takami A, Nakao S. Resveratrol induces cell cycle arrest and apoptosis in malignant NK cells via JAK2/STAT3 pathway inhibition. PLoS One. 2013;8(1), e55183. doi:10.1371/journal.pone.0055183 PONE-D-12-31673.

27. Lu CC, Chen JK. Resveratrol enhances perforin expression and NK cell cytotoxicity through NKG2D-dependent pathways. J Cell Physiol. 2010;223(2):343-51. doi:10.1002/jcp.22043.

28. Pashine A, Valiante NM, Ulmer JB. Targeting the innate immune response with improved vaccine adjuvants. Nat Med. 2005;11(4 Suppl):S63-8. doi:10.1038/nm1210

29. Claus M, Greil J, Watzl C. Comprehensive analysis of NK cell function in whole blood samples. J Immunol Methods. 2009;341(1-2):154-64. doi:10.1016/j.jim.2008.11.006.

30. Valiathan R, Lewis JE, Melillo AB, Leonard S, Ali KH, Asthana D. Evaluation of a flow cytometry-based assay for natural killer cell activity in clinical settings. Scand J Immunol. 2012;75(4):455-62. doi:10.1111/j.1365-3083.2011.02667.X.

31. Kim GG, Donnenberg VS, Donnenberg AD, Gooding W, Whiteside TL. A nove multiparametric flow cytometry-based cytotoxicity assay simultaneously immunophenotypes effector cells: comparisons to a $4 \mathrm{~h} 51 \mathrm{Cr}$-release assay. J Immunol Methods. 2007;325(1-2):51-66. doi:10.1016/j.jim.2007.05.013.

32. Prendergast GC, Smith C, Thomas S, Mandik-Nayak L, Laury-Kleintop L, Metz $R$, et al. Indoleamine 2,3-dioxygenase pathways of pathogenic inflammation and immune escape in cancer. Cancer Immunol Immunother. 2014;63(7):721-35. doi:10.1007/s00262-014-1549-4.

33. Pang $Y$, Norihisa $Y$, Benjamin D, Kantor RR, Young HA. Interferon-gamma gene expression in human B-cell lines: induction by interleukin-2, protein kinase $C$ activators, and possible effect of hypomethylation on gene regulation. Blood. 1992;80(3):724-32.

34. Zhang EY, Kong KF, Altman A. The yin and yang of protein kinase C-theta (PKCtheta): a novel drug target for selective immunosuppression. Adv Pharmacol. 2013;66:267-312. doi:10.1016/B978-0-12-404717-4.00006-8.

35. Anel A, Aguilo JI, Catalan E, Garaude J, Rathore MG, Pardo J, et al. Protein Kinase C-theta (PKC-theta) in Natural Killer Cell Function and Anti-Tumor Immunity. Front Immunol. 2012;3:187. doi:10.3389/fimmu.2012.00187.

36. Lim JC, Chan TK, Ng DS, Sagineedu SR, Stanslas J, Wong WS. Andrographolide and its analogues: versatile bioactive molecules for combating inflammation and cancer. Clin Exp Pharmacol Physiol. 2012;39(3):300-10. doi:10.1111/j.1440-1681.2011.05633.x

37. Ramroodi N, Khani M, Ganjali Z, Javan MR, Sanadgol N, Khalseh R et al. Prophylactic Effect of BIO-1211 Small-Molecule Antagonist of VLA-4 in the EAE Mouse Model of Multiple Sclerosis. Immunol Invest.44(7):694-712. doi:10.3109/08820139.2015.1085391.

38. Neri S, Mariani E, Meneghetti A, Cattini L, Facchini A. Calceinacetyoxymethyl cytotoxicity assay: standardization of a method allowing additional analyses on recovered effector cells and supernatants. Clin Diagn Lab Immunol. 2001:8(6):1131-5. doi:10.1128/CDLI.8.6.1131-1135.2001.

39. Cholujova D, Jakubikova J, Kubes M, Arendacka B, Sapak M, Ihnatko R, et al. Comparative study of four fluorescent probes for evaluation of natural killer cell cytotoxicity assays. Immunobiology. 2008;213(8):629-40. doi:10.1016/j.imbio.2008.02.006

\section{Submit your next manuscript to BioMed Central and take full advantage of:}

- Convenient online submission

- Thorough peer review

- No space constraints or color figure charges

- Immediate publication on acceptance

- Inclusion in PubMed, CAS, Scopus and Google Scholar

- Research which is freely available for redistribution

Submit your manuscript at www.biomedcentral.com/submit 